BMJ Open

Diabetes

Research

$\&$ Care

\section{Efficacy of clindamycin compared with amoxicillin-metronidazole after a 7-day regimen in the treatment of periodontitis in patients with diabetes: a randomized clinical trial}

To cite: Gómez-Sandoval JR, Robles-Cervantes JA, Hernández-González SO, et al. Efficacy of clindamycin compared with amoxicillinmetronidazole after a 7-day regimen in the treatment of periodontitis in patients with diabetes: a randomized clinical trial. BMJ Open Diab Res Care 2020;8:e000665. doi:10.1136/ bmjdrc-2019-000665

Received 14 February 2019 Revised 11 October 2019 Accepted 26 November 2019
Check for updates

(C) Author(s) (or their employer(s)) 2020. Re-use permitted under CC BY-NC. No commercial re-use. See rights and permissions. Published by BMJ.

For numbered affiliations see end of article.

Correspondence to Dr Arieh Roldán MercadoSesma;

arieh.mercado@academicos. udg.mx

\section{ABSTRACT}

Objective To determine the efficacy of clindamycin compared with amoxicillin-metronidazole after a 7-day regimen during nonsurgical treatment of periodontitis in patients with type 2 diabetes mellitus.

Research design and methods In this double-blind, randomized clinical trial, a total of 42 patients with chronic periodontitis and type 2 diabetes were included. Patients were randomly assigned to treatment with either clindamycin or amoxicillin-metronidazole three times a day during 7 days. Clinical determinations (probing depth, bleeding on probe, and plaque index) were performed to determine the extent and severity of periodontitis before and after the pharmacological treatment.

Results After 7 days of administration of clindamycin or amoxicillin-metronidazole, no differences were observed between the clinical determinations, probing depth $(0.44$ vs $0.50 \mathrm{~mm}, p=0.624$ ), plaque index ( 17.62 vs $15.88 \%$, $\mathrm{p}=0.910$ ), and bleeding on probing ( 16.12 vs $22.17 \%$, $p=0.163$ ), respectively. There were no adverse events in either group.

Conclusion The administration during 7 days of clindamycin or amoxicillin/metronidazole showed the same efficacy for the reduction of probing depth, plaque index, and bleeding on probing in patients with periodontitis and type 2 diabetes.

\section{INTRODUCTION}

Diabetes mellitus is a risk factor for gingivitis and periodontitis. Diabetic adults with poorly controlled glycemia had a 2.9-fold increased risk of having periodontitis compared with nondiabetic adult subjects. ${ }^{1}{ }^{2}$ It is estimated that periodontitis affects 740 million people worldwide. $^{23}$ The link between both pathologies is an altered immunoinflammatory response and changes in gingival microflora as a consequence of chronic hyperglycemia. This pathogenic flora has a relationship with worsened periodontitis. The complications of chronic periodontitis are the progressive

\section{Significance of this study}

What is already known about this subject?

- Diabetes mellitus is a risk factor for periodontitis. The complications of chronic periodontitis are the progressive destruction of the periodontal ligament and alveolar bone. The use of mechanical debridement is the standard therapy. Because this procedure has some limitations the use of antibiotics is an option. However, some antibiotics show more efficacy.

What are the new findings?

- Clindamycin during 7 days has the same efficacy as amoxicillin/metronidazole. Clindamycin is a good option in periodontal therapy.

- Short courses of antibiotic therapy reduce adverse events.

How might these results change the focus of research or clinical practice?

- The use of short courses of antibiotic therapy is a good option which improves adherence, is less expensive, and has fewer adverse events.

destruction of the periodontal ligament and alveolar bone. ${ }^{4-7}$ Standard periodontal treatment includes mechanical debridement to remove biofilm and calculus from the affected root surfaces. ${ }^{89}$ Because this procedure has some limitations, the use of antimicrobial agents is an option to eradicate pathogenic bacteria in deep pockets, root furcations, and concavities. In this sense, the objective of periodontal antibiotic therapy is to reduce the number of periodontal pathogens and produce a healthy periodontium in a short time. $^{10} 11$ The most used treatment is the combination of amoxicillin with metronidazole (AMX-MET) due their synergistic effect 
and their wide spectrum of activity. ${ }^{12}$ However, there are reports of higher resistance in some pathogens compared with other antibiotics. Rams et al, mentioned a resistance of $55 \%$ vs $30.3 \%$ with the use of AMX-MET compared with clindamycin, respectively. ${ }^{13}$ Clindamycin is a semisynthetic derivative of lincomycin, used in the treatment of dental, bone or joint infections. Moreover, it has been used in the treatment of foot infections in patients with diabetes and in the prevention of endocarditis. ${ }^{14-16}$

In spite of both antibiotic regimens being effective against anaerobic microorganisms, there are no studies that compare both therapies in the treatment of periodontitis in patients with diabetes.

The purpose of the present study was to determine the efficacy of systemic clindamycin compared with amoxicillin/metronidazole in the treatment of periodontitis during nonsurgical periodontal treatment in patients with type 2 diabetes.

\section{RESEARCH DESIGN AND METHODS}

Study design

A parallel, randomized, double-blind, single-center clinical trial was designed to compare the efficacy of two antibiotic therapies. The study was carried out on patients at the Integral Dentistry Clinics of the University Center of Health Sciences of the University of Guadalajara in Jalisco, Mexico. The participants attended for dental care from August 2015 to December 2016. The study protocol was approved by the ethical committee of the Universitary Center of Health Sciences of University of Guadalajara and conducted according to Good Clinical Practice and the principles of the Declaration of Helsinki. All patients provided written informed consent before the initiation of study procedures. The protocol was registered in Clinicaltrials.gov NCT 03374176.

The sample size was calculated with a $95 \%$ confidence level and statistical power of $80 \%$. A SD of $1.0 \mathrm{~mm}$ with an expected difference of $1.0 \mathrm{~mm}$ probing depth reduction between treatments. This resulted in a total of 14 patients per arm; however, considering an attrition of about $20 \%$, it was established that least 21 subjects should be included in each treatment group.

\section{Patient population}

Criteria for selection

Patients of both sexes (aged $>18-70$ years) with a diagnosis of chronic periodontitis moderately localized according to the 1999 International World Workshop for a Classification of Periodontal Diseases and Conditions and a history of type 2 diabetes with $\mathrm{a}_{\mathrm{AlC}}<8 \%$ and a fasting plasma glucose $(\mathrm{FPG})<180 \mathrm{mg} / \mathrm{dL}$, were chosen. Diabetes should not have been diagnosed more than 10 years previously. Patients with aggressive periodontitis, pregnant or lactating females, persons who required antibiotic premedication for the performance of periodontal examination and treatment or who had received antibiotic treatment in the previous 3 months were excluded. A history of anti-inflammatory therapy during the preceding 6 months or who had received a course of periodontal treatment within the previous 6 months, who were allergic to penicillin, metronidazole or clindamycin, who smoked or were not able to provide consent to participate in the study were also excluded. All the included participants received the appropriate treatment for glucose control as determined by their specialist doctor.

\section{Intervention}

Participants were randomly allocated $1: 1$ to receive $300 \mathrm{mg}$ clindamycin plus placebo or $500 \mathrm{mg}$ amoxicillin plus $250 \mathrm{mg}$ metronidazole and allocated using a random numbers generator. AMX and MET are distinctive pills, so we decided to use placebo pills plus clindamycin with the objective of eliminating possible bias. These drugs were blinded in bottles with the same characteristics and neither the patient nor the researcher knew what treatment was being applied. Subjects in both groups were instructed to take the treatment three times a day for 7 days. The procedure was explained and managed by a previously trained nurse.

\section{Assessments}

Participants were evaluated twice. A complete periodontal examination was conducted, including a full medical and dental history, an intraoral examination and full-mouth periodontal probing. A radiographic examination was undertaken using either periapical films or a pantomogram. Periodontal therapy was initiated within 1 month of the baseline screening examination. A standard cycle of periodontal therapy consisting of oral hygiene instruction, supragingival and subgingival mechanical instrumentation scaling and root planing (SRP) was performed by two experienced therapists.

\section{Clinical parameters}

Clinical parameters were assessed using a North Caroline Periodontal Probe by the calibrated examiner at six sites. Full-mouth plaque scores were recorded by assigning a binary score to each surface ( 1 for plaque present, 0 for absent) and by calculating the proportion of all tooth surfaces on which plaque was detected using a disclosing tablet. Similarly, a full-mouth proportion of bleeding sites was calculated after dichotomously assessing bleeding on probing from the bottom of the pocket with a manual probe with a force of $0.3 \mathrm{~N}$. Full-mouth probing pockets depth (PPD) and recession of the gingival margin were recorded at the same time with measurements rounded to the nearest millimeter.

\section{Statistical analysis}

Age, $\mathrm{FPG}, \mathrm{Hb}_{\mathrm{Al}}$, tooth, and sounding depth were presented as means and SD. The intragroup differences were calculated with Wilcoxon rank test. The intergroup differences were calculated with Mann-Whitney test. Sex, bacterial plaque, and bleeding to the sounding were summarized using proportions and analyzed with $\chi^{2}$. In all analyses, a $\mathrm{p}<0.05$ (two tailed) was considered statistically significant. 


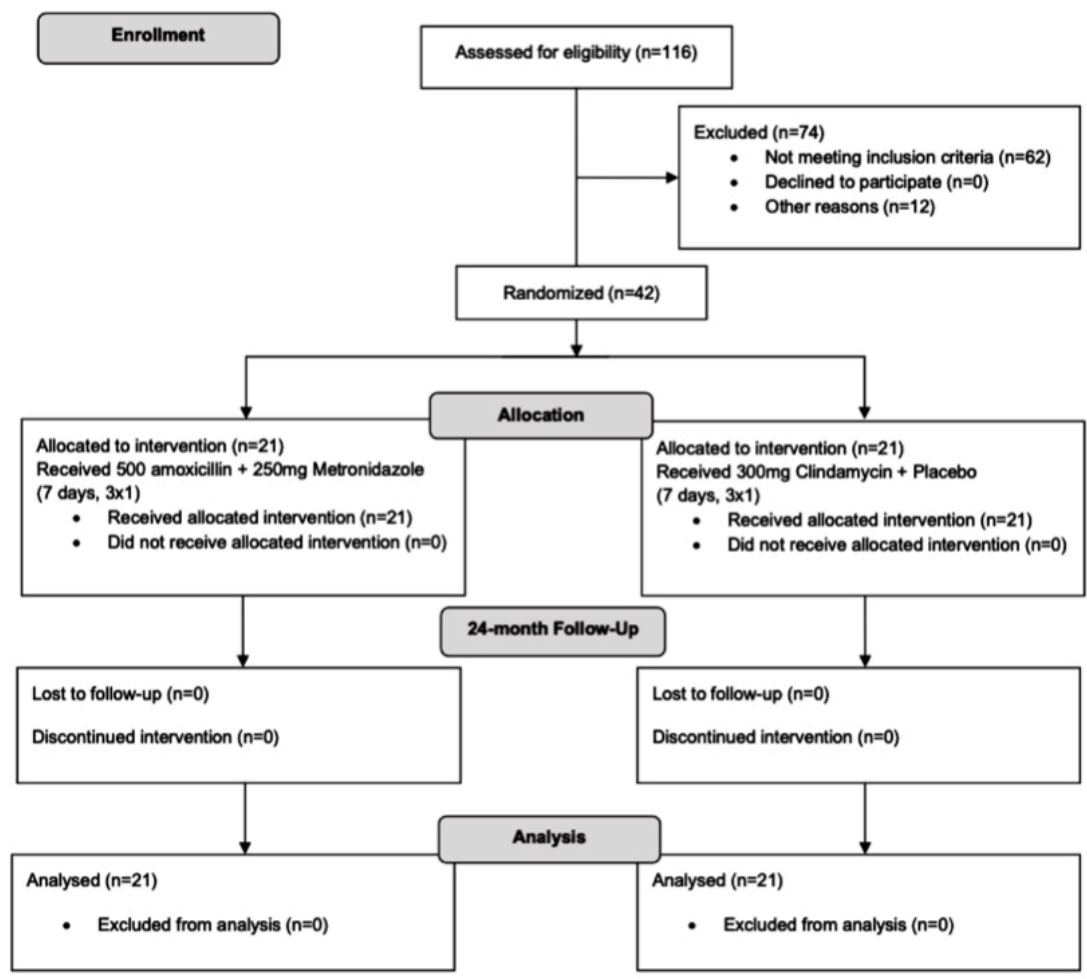

Figure 1 Flow chart of the study design

All statistical analyses were conducted using SPSS software (IBM, Armonk, New York, USA) V.21.

\section{RESULTS}

A total of 42 patients were enrolled in this study; figure 1 shows a flow diagram. The comparative analysis of the baseline measurements showed no differences between study groups (table 1). After antimicrobial therapy, no significant intragroup differences in probing depth,

Table 1 Basal demographics characteristics and clinical parameters of study groups

\begin{tabular}{lccl}
\hline & AMX+MET & Clindamycin & P value \\
\hline Sex, F/M (\%)* & $10 / 11(48 / 53)$ & $14 / 7(67 / 33)$ & 0.212 \\
\hline Age, years & $52.5(8.0)$ & $52.0(10.6)$ & 0.950 \\
\hline FPG, mg/dL & $134.1(23.3)$ & $136.3(25.7)$ & 0.950 \\
\hline HbA1C, \% & $7.1(0.4)$ & $7.3(0.4)$ & 0.120 \\
\hline Tooth, $n$ & $25(3)$ & $24(5)$ & 0.650 \\
\hline Sites, $n$ & $147(25)$ & $144(29)$ & 0.705 \\
\hline Probing depth, mm & $2.4(0.6)$ & $2.6(0.6)$ & 0.180 \\
\hline Plaque index, (\%) & $40.4(22.9)$ & $40.7(21.9)$ & 0.850 \\
\hline $\begin{array}{l}\text { Bleeding on probing } \\
\text { (\%) }^{*}\end{array}$ & $42.4(24.2)$ & $55.6(25.8)$ & 0.070 \\
\hline
\end{tabular}

$\mathrm{P} \leq 0.05$.

*Pearson $\chi^{2}$ test. U-Mann-Whitney test.

†Values in mean (SD).

$\mathrm{AMX}+\mathrm{MET}$, amoxicillin with metronidazole; F, female; FPG,

fasting plasma glucose; $M$, male. plaque index, and bleeding on probing were observed. There were no statistically significant differences between the groups when the clinical variables were evaluated (figures 2 and 3 ).

No loss of teeth between groups compared with baseline was reported. No serious adverse events occurred during the study.

\section{DISCUSSION}

Complications due to diabetes have negative effects on different aspects of patients' health: economics, quality of life, and self-esteem. Periodontitis is a common complication in patients with diabetes, not frequently mentioned. Poor glycemic control associated with periodontitis can modify the connective tissues response and the progressive destruction of periodontal structures. Periodontal treatment may have a positive effect on hyperglycemia, independently of diabetic treatment. ${ }^{17-19}$

Recent evidence has shown that the use of adjunct systemic antibiotics with SRP in patients with diabetes is inconclusive. ${ }^{10-12}$ Santos $e t a l$, in a systematic review, evaluated the effect of different antibiotics on periodontal parameters in patients with diabetes. The results showed a positive significant effect with the use of SRP plus antibiotics, reducing the probing depth and bleeding in probing..$^{20}$ Our results showed a similar reduction in both parameters with the use of clindamycin or amoxicillin-metronidazole. In addition, these findings are in concordance to other randomized clinical trials that had used systemic antibiotics in similar populations. ${ }^{21-25}$ 


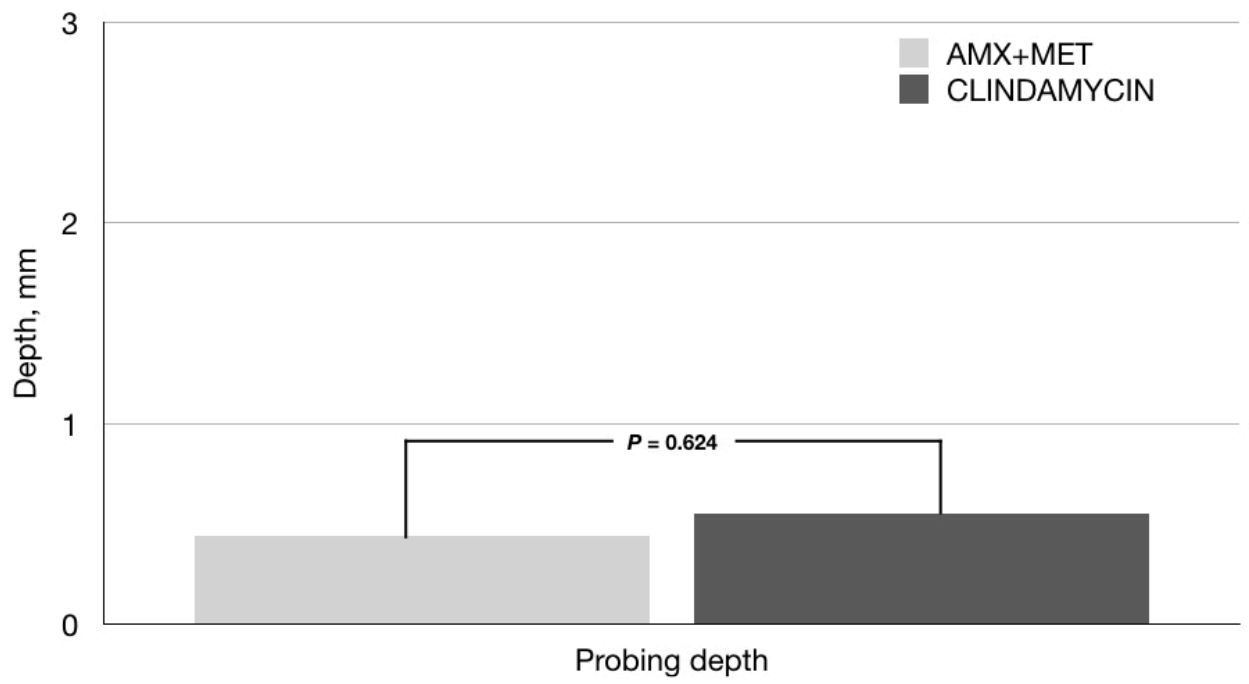

Figure 2 Comparison between groups in final sounding depth. Value in mean. $P \leq 0.05$. Mann-Whitney test. AMX, amoxicillin; MET, metronidazole.

Several authors refer to SRP plus amoxicillinmetronidazole as the most effective therapy for periodontitis in patients with diabetes when compared with several antibiotics. ${ }^{26-29}$ However, no studies compare AMX-MET with clindamycin. Clindamycin is a broadspectrum antibiotic, active against aerobic and anaerobic bacteria including coverage against beta-lactamase producing pathogens. It could be considered an option in the treatment of diabetic infections in different sites. ${ }^{30}$

Unlike other studies, the present trial shows that clinical benefit can be achieved with 7 days of antibiotic treatment vs the 14 days prescribed by other authors. ${ }^{31}$ According to a rational use of antibiotics, the duration of treatment should be the shortest possible and most acute oral infections are resolved in less than 7 days. ${ }^{32}$ Moreover, the use of short courses have some advantages: fewer adverse events, more adhesion, lower costs, and so on. ${ }^{32}$ There is a tendency to use higher doses for a shorter time, but the evidence about this practice is not conclusive. ${ }^{33}$ We consider a better option is to use standard doses for a shorter time as complement to periodontitis treatment.

The intragroup significant differences between baseline and the final visit were observed in both groups. The efficacy of amoxicillin and metronidazole in the treatment of periodontitis is established evidence. However, the use of clindamycin is a new option in oral infections.

In addition, in the present study, no teeth were reported to have been lost in either group. The principal limitation of the present study was the absence of a group with SRP plus placebo. This study design, using a placebo group, could help us to evaluate the efficacy of clindamycin versus SRP alone. However, this study shows that clindamycin is a new option similar to AMX-MET for periodontitis treatment in patients with diabetes.

\section{CONCLUSION}

The administration during 7 days of clindamycin or amoxicillin/metronidazole showed the same efficacy for

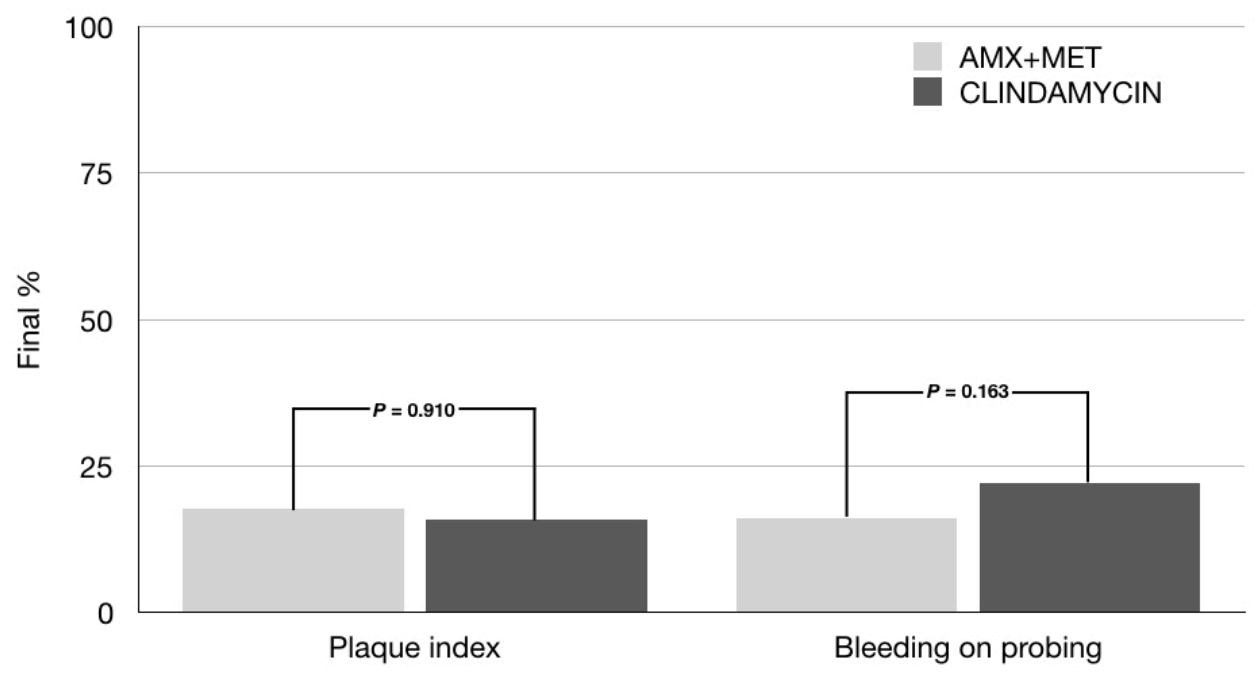

Figure 3 Comparison between groups in final clinical assessments. Value in mean. $P \leq 0.05 . \chi^{2}$-test. AMX, amoxicillin; MET, metronidazole. 
reducing probing depth, plaque index, and bleeding on probing in patients with periodontitis and type 2 diabetes.

\section{Author affiliations}

'Departamento de Clínicas Odontológicas Integrales, Instituto de Invesigación en Odontología, Especialidad en Periodoncia, Universidad de Guadalajara, Centro Universitario de Ciencias de la Salud, Guadalajara, Jalisco, Mexico ${ }^{2}$ Servicio de Medicina Interna, Instituto Jalisciense de Cirugía Reconstructiva, Secretaría de Salud Jalisco, Guadalajara, Jalisco, Mexico

${ }^{3}$ Unidad de Investigación Biomédica 02 y División de Investigación en Salud, Unidad Médica de Alta Especialidad Hospital de Especialidades, Centro Médico Nacional de Occidente, Instituto Mexicano del Seguro Social, Guadalajara, Jalisco, Mexico

${ }^{4}$ Diabetes sin Complicaciones S.A de C.V, Zapopan, Jalisco, México

${ }^{5}$ Departamento de Salud enfermedad como proceso individual and Centro de Investigación Multidisciplinaria en Salud, Universidad de Guadalajara, Centro Universitario de Tonalá, Tonalá, Jalisco, Mexico

Acknowledgements We appreciate the comments and correction style of Paul Riordan of Write 2 Publish. We also appreciate the comments and support of Raúl Baptista Rosas and Luis Cortes of Research Department of CUTonalá.

Contributors JRGS, JARC, SOHG, MCEB, and ARMS participated in the design of the study. JRGS, JARC, SOHG, RMS, VMR, and KCMC participated in data interpretation. MCEB and ARMS performed the statistical analysis of the data. JRGS, RMS, and VMR participated in recruited and evaluation participants and data collection. All authors helped to draft the manuscript and read and approved the final manuscript.

Funding The authors have not declared a specific grant for this research from any funding agency in the public, commercial or not-for-profit sectors.

Competing interests None declared.

Patient consent for publication Not required.

Provenance and peer review Not commissioned; externally peer reviewed.

Data availability statement Data are available upon reasonable request. All data relevant to the study are included in the article or uploaded as supplementary information.

Open access This is an open access article distributed in accordance with the Creative Commons Attribution Non Commercial (CC BY-NC 4.0) license, which permits others to distribute, remix, adapt, build upon this work non-commercially, and license their derivative works on different terms, provided the original work is properly cited, appropriate credit is given, any changes made indicated, and the use is non-commercial. See: http://creativecommons.org/licenses/by-nc/4.0/.

ORCID iD

Arieh Roldán Mercado-Sesma http://orcid.org/0000-0002-9025-9328

\section{REFERENCES}

1 Taylor JJ, Preshaw PM, Lalla E. A review of the evidence for pathogenic mechanisms that may link periodontitis and diabetes. $J$ Clin Periodontol 2013;40 Suppl 14:S113-34

2 Tsai C, Hayes C, Taylor GW. Glycemic control of type 2 diabetes and severe periodontal disease in the US adult population. Community Dent Oral Epidemiol 2002;30:182-92.

3 Kassebaum NJ, Bernabe E, Dahiya M, et al. Global burden of severe periodontitis in 1990-2010: a systematic review and metaregression. J Dental Res 2014;93:1045-53.

4 Marchetti E, Monaco A, Procaccini L, et al. Periodontal disease: the influence of metabolic syndrome. Nutr Metab 2012;9.

5 Lalla E, Papapanou PN. Diabetes mellitus and periodontitis: a tale of two common interrelated diseases. Nat Rev Endocrinol 2011;7:738-48.

6 Liu R, Desta T, He H, et al. Diabetes alters the response to bacteria by enhancing fibroblast apoptosis. Endocrinology 2004:145:2997-3003.

7 Liu R, Bal HS, Desta T, et al. Diabetes enhances periodontal bone loss through enhanced resorption and diminished bone formation. $J$ Dent Res 2006;85:510-4.

8 Kadkhoda Z, Tari SR, Owlia P, et al. Comparison of 1-periodontal indices and cultural Porphyromonas gingivalis colony count in aggressive periodontitis patients treated by scaling and rootplanning with or without metronidazole gel. J Dent 2012;9:50.
9 Greenstein G. Full-Mouth therapy versus individual quadrant root planing: a critical commentary. J Periodontol 2002;73:797-812.

10 Haffajee AD, Socransky SS, Gunsolley JC. Systemic anti-infective periodontal therapy. A systematic review. Ann Periodontol 2003;8:115-81.

11 Herrera D, Sanz M, Jepsen S, et al. A systematic review on the effect of systemic antimicrobials as an adjunct to scaling and root planing in periodontitis patients. J Clin Periodontol 2002;29:136-59.

12 Soares GMS, Mendes JAV, Silva MP, et al. Metronidazole alone or with amoxicillin as adjuncts to non-surgical treatment of chronic periodontitis: a secondary analysis of microbiological results from a randomized clinical trial. J Clin Periodontol 2014;41:366-76.

13 Rams TE, Degener JE, van Winkelhoff AJ. Antibiotic resistance in human chronic periodontitis microbiota. $J$ Periodontol 2014;85:160-9.

14 Brook I. Spectrum and treatment of anaerobic infections. $J$ Infect Chemother 2016;22:1-13.

15 Segura-Egea JJ, Gould K, Sen BH, et al. Antibiotics in Endodontics: a review. Int Endod J 2017;50:1169-84.

16 Brook I, Lewis MAO, Sándor GKB, et al. Clindamycin in dentistry: more than just effective prophylaxis for endocarditis? Oral Surg Oral Med Oral Pathol Oral Radiol Endod 2005;100:550-8.

17 Mealey BL, Ocampo GL. Diabetes mellitus and periodontal disease. Periodontol 2000 2007;44:127-53.

18 Lakschevitz F, Aboodi G, Tenenbaum H, et al. Diabetes and periodontal diseases: interplay and links. Curr Diab Rev 2011;7:433-9.

19 Miranda TS, Feres M, Retamal-Valdés B, et al. Influence of glycemic control on the levels of subgingival periodontal pathogens in patients with generalized chronic periodontitis and type 2 diabetes. $J$ Appl Oral Sci 2017:25:82-9.

20 Santos CMML, Lira-Junior R, Fischer RG, et al. Systemic antibiotics in periodontal treatment of diabetic patients: a systematic review. PLoS One 2015;10:e0145262.

21 Skurska A, Dolinska E, Pietruska M, et al. Effect of nonsurgical periodontal treatment in conjunction with either systemic administration of amoxicillin and metronidazole or additional photodynamic therapy on the concentration of matrix metalloproteinases 8 and 9 in gingival crevicular fluid in patients with aggressive periodontitis. BMC Oral Health 2015;15:63-7.

22 Guzeldemir-Akcakanat E, Gurgan CA. Systemic moxifloxacin vs amoxicillin/metronidazole adjunct to non-surgical treatment in generalized aggressive periodontitis. Med Oral 2015;1:e441-9.

23 Jepsen K, Jepsen S. Antibiotics/antimicrobials: systematic and local administration in the therapy of mild to moderately advanced periodontitis. Periodontology 2016;2000:82-112.

24 Mombelli A. Antimicrobial profiles of periodontal pathogens and systemic antimicrobial therapy. J Clin Periodontol 2005;32:891-2.10.1111/j.1600-051X.2005.00807.x

25 Matarazzo F, Figueiredo LC, Cruz SEB, et al. Clinical and microbiological benefits of systemic metronidazole and amoxicillin in the treatment of smokers with chronic periodontitis: a randomized placebo-controlled study. J Clin Periodontol 2008;35:885-96.

26 Mestnik MJ, Feres M, Figueiredo LC, et al. Short-Term benefits of the adjunctive use of metronidazole plus amoxicillin in the microbial profile and in the clinical parameters of subjects with generalized aggressive periodontitis. J Clin Periodontol 2010;37:353-65.

27 Silva MP, Feres M, Oliveira Sirotto TA, et al. Clinical and microbiological benefits of metronidazole alone or with amoxicillin as adjuncts in the treatment of chronic periodontitis: a randomized placebo-controlled clinical trial. J Clin Periodontol 2011;38:828-37.

28 Miranda TS, Feres M, Perez-Chaparro PJ, et al. Metronidazole and amoxicillin as adjuncts to scaling and root planing for the treatment of type 2 diabetic subjects with periodontitis: 1-year outcomes of a randomized placebo-controlled clinical trial. J Clin Periodontol 2014;41:890-9.

29 Tamashiro NS, Duarte PM, Miranda TS, et al. Amoxicillin plus metronidazole therapy for patients with periodontitis and type 2 diabetes: a 2-year randomized controlled trial. J Dent Res 2016:95:829-36.

30 Spížek J, Řezanka T, Lincomycin RT. Lincomycin, clindamycin and their applications. Appl Microbiol Biotechnol 2004;64:455-64.

31 Flynn TR. What are the antibiotics of choice for odontogenic infections, and how long should the treatment course last? Oral Maxillofac Surg Clin North Am 2011;23:519-36.

32 Oberoi SS, Dhingra C, Sharma G, et al. Antibiotics in dental practice: how justified are we. Int Dent J 2015;65:4-10.

33 Herrera D, Matesanz P, Bascones-Martínez A, et al. Local and systemic antimicrobial therapy in periodontics. J Evid Based Dent Pract 2012;12:50-60. 